\title{
Heterosis and correlation in interspecific and intraspecific hybrids of cotton
}

\author{
S. Munir ${ }^{1}$, S.B. Hussain ${ }^{1}$, H. Manzoor ${ }^{3}$, M.K. Quereshi ${ }^{1}$, M. Zubair ${ }^{4}$, \\ W. Nouman ${ }^{4}$, A.N. Shehzad ${ }^{2}$, S. Rasul ${ }^{3}$ and S.A. Manzoor ${ }^{4}$ \\ ${ }^{1}$ Department of Plant Breeding and Genetics, \\ Faculty of Agricultural Sciences and Technology, \\ Bahauddin Zakariya University, Multan, Punjab, Pakistan \\ ${ }^{2}$ Department of Agronomy, Faculty of Agricultural Sciences and Technology, \\ Bahauddin Zakariya University, Multan, Punjab, Pakistan \\ ${ }^{3}$ Institute of Molecular Biology and Biotechnology, \\ Bahauddin Zakariya University, Multan, Punjab, Pakistan \\ ${ }^{4}$ Department of Forestry, Faculty of Agricultural Sciences and Technology, \\ Bahauddin Zakariya University, Multan, Punjab, Pakistan \\ Corresponding author: S.A. Manzoor \\ E-mail: amir.kzd@gmail.com \\ Genet. Mol. Res. 15 (2): gmr. 15028083 \\ Received November 18, 2015 \\ Accepted January 18, 2016 \\ Published June 24, 2016 \\ DOI http://dx.doi.org/10.4238/gmr.15028083
}

\begin{abstract}
Interspecific and intraspecific hybrids show varying degrees of heterosis for yield and yield components. Yield-component traits have complex genetic relationships with each other. To determine the relationship of yield-component traits and fiber traits with seed cotton yield, six lines (Bt. CIM-599, CIM-573, MNH-786, CIM-554, BH-167, and GIZA-7) and three test lines (MNH-886, V4, and CIM-557) were crossed in a line $\mathrm{x}$ tester mating design. Heterosis was observed for seed cotton yield, fiber traits, and for other yield-component traits. Heterosis in interspecific hybrids for seed cotton yield was more prominent than in intraspecific hybrids. The interspecific hybrid Giza-7 x MNH-886 had the highest heterosis (114.77), while among intraspecific hybrids, CIM554 x CIM-557 had the highest heterosis (61.29) for seed cotton yield.
\end{abstract}


A major trait contributing to seed cotton yield was bolls/plant followed by boll weight. Correlation studies revealed that bolls/plant, boll weight, lint weight/boll, lint index, seed index, lint/seed, staple length, and staple strength were significantly and positively associated with seed cotton yield. Selection based on boll weight, boll number, lint weight/boll, and lint index will be helpful for improving cotton seed yield.

Key words: Heterosis; Correlation; Interspecific hybrids; Intraspecific hybrids

\section{INTRODUCTION}

Heterosis represents a method of increasing cotton fiber yield and quality, which is the main objective of breeding programs (Meredith and Brown, 1998). Hybrids are capable of providing greater yields than commercial cultivars, although high yields can be gained through the use of an appropriate crossing plan (Wu et al., 2004). Approximately $20 \%$ of the total global acreage has been covered by cotton hybrids since 2000 (Dong et al., 2006).

Cotton contributes $6.7 \%$ of the value added to agriculture and $1.4 \%$ of the GDP of Pakistan. In 2013/14, cotton production was 12.8 million bales, which was less than the 13 million bales produced in the previous year (2012/13) and equal to a yield drop of $2 \%$ (Anonymous, 2014). To enhance yield, hybrids should be developed through heterosis (Wu et al., 2004). Heterosis has been observed in cotton for reproductive and vegetative growth, fiber quality, and photosynthesis (Chen et al., 2005). Bolls/unit area and boll weight are major contributors to yield and hybrid vigor (Tang et al., 1993). Heterobeltiosis varied from 0.02 to $93.83 \%$ and mid-parent heterosis ranged from 0.19 to $122.7 \%$ for lint yield in intraspecific and interspecific hybrids (Gupta and Singh, 1987). Favorable heterosis was reported for seed cotton yield and bolls/plant (Katageri et al., 1991), and boll weight, bolls/plant, sympodia/ plant, and seed cotton yield, displayed significant heterosis in a separate study (Keerio et al., 1996). Interspecific hybrids give rise to larger range of heterosis than do intraspecific hybrids for seed cotton yield. Interspecific hybrids (Gossypium hirsutum x Gossypium barbadense) displayed $157.2 \%$ heterosis, while intraspecific (i.e., intra-hirsutum and intra-barbadense) hybrids resulted in 33.7 and $28.3 \%$ heterosis, respectively (Soomro et al., 1996). A high level of heterosis has been reported in both intraspecific and interspecific hybrids of cotton for lint yield and yield components (Marani, 1967; Cole et al., 2009). Boll number is reported to be a major yield component, which affects hybrid yield (Worley et al., 1974; Zeng and Wu, 2012). In some cases, yield heterosis is associated with both boll weight and boll number (Marani, 1968).

Cotton fiber yield and quality can be increased by a better understanding of yield and quality traits as well as the relationships between them, because genotypic correlation is inherited via these two variables (Fonseca and Patterson, 1968). In cotton, seed yield and monopodial branches are positively correlated (Iqbal et al., 2003), while fiber quality and yield traits are negatively correlated (Azhar et al., 1984).

A negative correlation was observed between fiber strength and yield (Green and Culp, 1990), whereas a complex association was found between fiber strength and length with yield (Coyle and Smith, 1997). Cotton breeding is performed to break these complicated linkages, so that both yield and fiber quality can be improved. A non-significant positive correlation 
was reported between fiber quality and yield traits in cotton (Zhou, 1986). A non-significant relationship was also found between boll weight and lint yield, while a significant correlation was reported for boll number with seed cotton yield and lint yield, respectively (Cole et al., 2009; Jenkins et al., 2009). However, higher boll numbers in cotton hybrids have resulted from the cumulative effect of both higher numbers of fruiting nodes and boll retention (Galal et al., 1966). In G. hirsutum, boll number heterosis is attributed to boll retention, whereas in $G$. barbadense it is related to a higher number of fruiting nodes (Marani, 1968).

Interspecific and intraspecific hybrids have been developed to gain high seed cotton yield, wide adaptation, and good fiber quality. Therefore, the main objective of the current study was to evaluate traits associated with a higher level of heterosis for yield, and to investigate the associations between yield, yield components, and fiber traits.

\section{MATERIAL AND METHODS}

The experiment was conducted in the fields of the department of Plant Breeding and Genetics, Bahauddin Zakariya University, Multan, Pakistan on loamy soil. Nine parental genotypes were used to develop hybrids: Bt. CIM-599, CIM-573, MNH-786, CIM-554, BH-167, GIZA-7, MNH-886, V4, and CIM-557. A 6 x 3 (line x tester) mating design was used. Among female parental cultivars, five were G. hirsutum species (Bt. CIM-599, CIM573, MNH-786, CIM-554, BH-167), while GIZA-7 was a cultivar of G. barbadense species. Among male parents, MNH-886 and CIM-557 were local cultivars whileV4 was an exotic cultivar. Seeds of all cultivars were collected from different research stations in Pakistan. Hybrids were developed by manual pollination. Fifteen intraspecific and three interspecific hybrids were developed, which were evaluated during the summer of 2013. The experiment was conducted in a randomized complete block design with three replicates. Hand sowing was performed with spacings of 12 inches between plants and 30 inches between rows. Irrigation, fertilizer, thinning, and cultural practices were performed as required.

Data were collected for bolls/plant TBP (total balls per plant), monopodia/plant (Mono), sympodia/plant (Sym), node of first fruiting branch (NFB), total nodes (TN), and fruiting nodes (FN) for three plants from each replicate to evaluate the contribution of morphological traits towards yield and heterosis. Boll picking was performed over three time intervals and bolls picked from each plant were used to determine boll weight (BW), seeds per boll (SB), lint weight (LW), ginning out turn (GOT), lint index (LI), seed index (SI), seed cotton/seed (SCS), seed weight/seed (SWS), lint/seed (LS), and seed cotton yield/plant (YP). Worley et al. (1974)'s method was used to calculate the seed cotton/seed (SCS), seed weight/ seed (SWS), and lint/seed (LS). The seed index was the weight of 100 seeds and the lint index was the lint obtained from 100 seeds. Fiber traits, i.e., micronaire value (Mic),staple length (SL), and staple strength (SS), were determined using a high volume instrument (HVI; USTER, Switzerland). Data collected were subjected to biometrical analysis to estimate heterosis and heterobeltiosis and to analyze correlations.

\section{RESULTS}

\section{Heterosis and heterobeltiosis}

Heterotic effects and heterobeltiosis of 15 intraspecific and three interspecific hybrids 


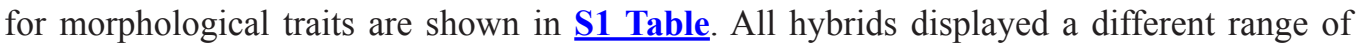
heterosis and heterobeltiosis for each trait.

For bolls/plant, the cross BH-167 x MNH-886 gave maximum heterosis (38.34) followed by BH-167 x V4 (35.85). All hybrids resulted inpositive heterosis except for two hybrids. Hybrid BH-167 x V4 showed the highest value for heterobeltiosis (15.75) followed by hybrid CIM-554 x MNH-886 (14.35). Among interspecific hybrids, the Giza-7 x MNH-886 hybrid showed the highest level of heterosis (52.77) and heterobeltiosis (22.57). No negative values were observed for heterosis and heterobeltiosis in interspecific hybrids for bolls/plant (Figure 1).

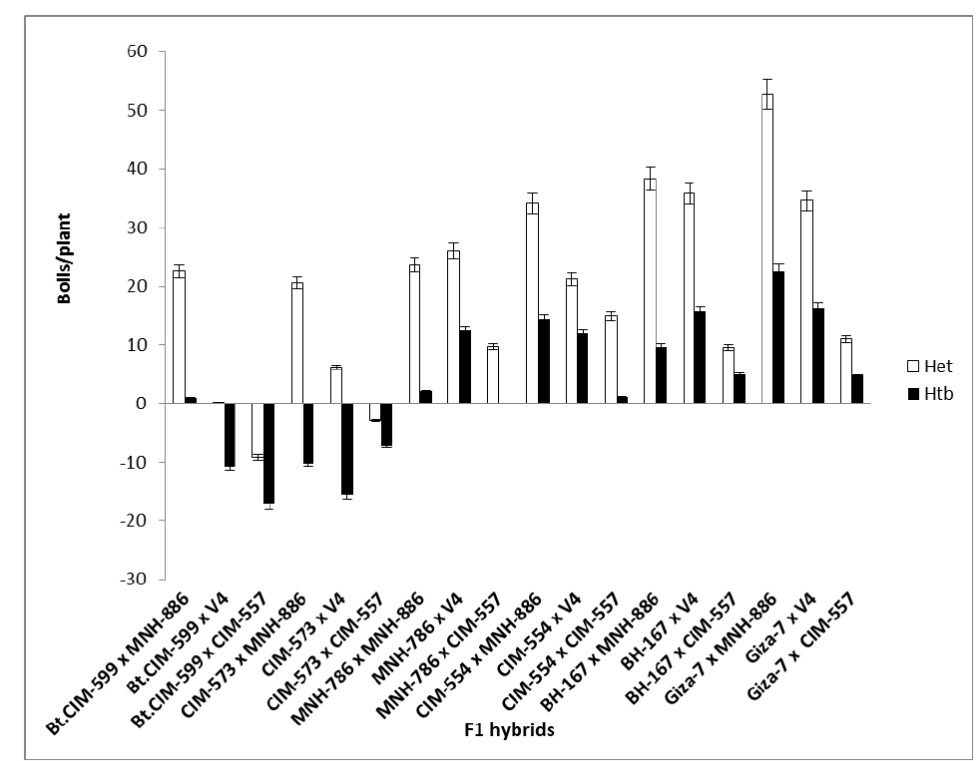

Figure 1. Results of heterosis and heterobeltosis for bolls/plant in intraspecific and interspecific hybrid.

The trait monopodia/plant contributes to yield, and heterosis of this trait is desired. However, due to insect infestations and increased vegetative growth, breeders prefer varieties with fewer monopodial branches. Six intraspecific and one interspecific hybrid showed positive heterosis for this trait. For the intraspecific hybrids, the maximum value for heterosis was shown by the cross BH-167 x MNH-886 (33.33), while negative heterosis was observed forMNH-786 x V4 (-76.29). The Giza-7 x MNH-886 hybrid showed positive heterosis (8.38). Except for three crosses, all intraspecific crosses showed positive heterosis for the trait sympodia/plant. The BH-167 x V4 hybrid had the highest value for heterosis (32.33). MNH786 x V4 exhibited the highest heterobeltiosis value (10.61) among intraspecific hybrids. Three interspecific hybrids showed positive heterosis, but the highest value was observed in Giza-7 x V4 for heterosis (43.96) and heterobeltiosis (35.02), as shown in Figure 2.

The number of sympodia increases when the first sympodia branch (NFB) arises at an early node; therefore, negative heterosis is more desirable in NFB. Three hybrids showed negative heterosis while the highest negative value was observed in MNH-786 x MNH-886 (-5.37). The Bt.CIM-599 x MNH-886 cross gave the maximum negative value for heterobeltiosis (-10.92). Heterosis and heterobeltiosis values in interspecific hybrids were 
obtained in a desirable direction (negative). The maximum negative value for heterosis (-9.82) and heterobeltiosis (-28.43) was obtained by Giza-7 x MNH-886 for NFB (1 Table). For nodes/plant, the maximum value was observed for the hybrid MNH-786 x V4 (24.03) for heterosis while theCIM-554 xMNH-886 hybrid gave the highest value for heterobeltiosis (10.90) among all hybrids.

The higher the number of fruiting nodes, the higher the chance of producing more fruiting bolls. The Bt.CIM-599 x V4 hybrid showed the highest heterosis (42.79) among all intraspecific and interspecific hybrids, with all interspecific hybrids showing positive heterosis for this trait. Heterosis and heterobeltiosis values for traits contributing to yield are shown in S2 Table. Positive heterosis was observed in all intraspecific and interspecific hybrids for boll weight. The highest heterosis value was shown by the CIM-554 x CIM-557 hybrid (32.05) (Figure 3) and for heterobeltiosis, the highest value among intraspecific hybrids was given by Bt.CIM-599 x V4 (28.18). Positive and maximum heterosis and heterobeltiosis values were obtained by Giza-7 x V4 at 44.73 and 31.86, respectively. Positive and negative values for heterosis and heterobeltiosis were also observed for boll weight. The BH-167 x V4 hybrid gave the highest value of heterosis (44.76) for seeds/boll among intraspecific hybrids, while for heterobeltiosis, the highest value was given by the BH-167 x V4 hybrid (39.14). The Giza$7 \mathrm{x}$ V4 hybrid gave the highest values for both heterosis (32.29) and heterobeltiosis (31.19).

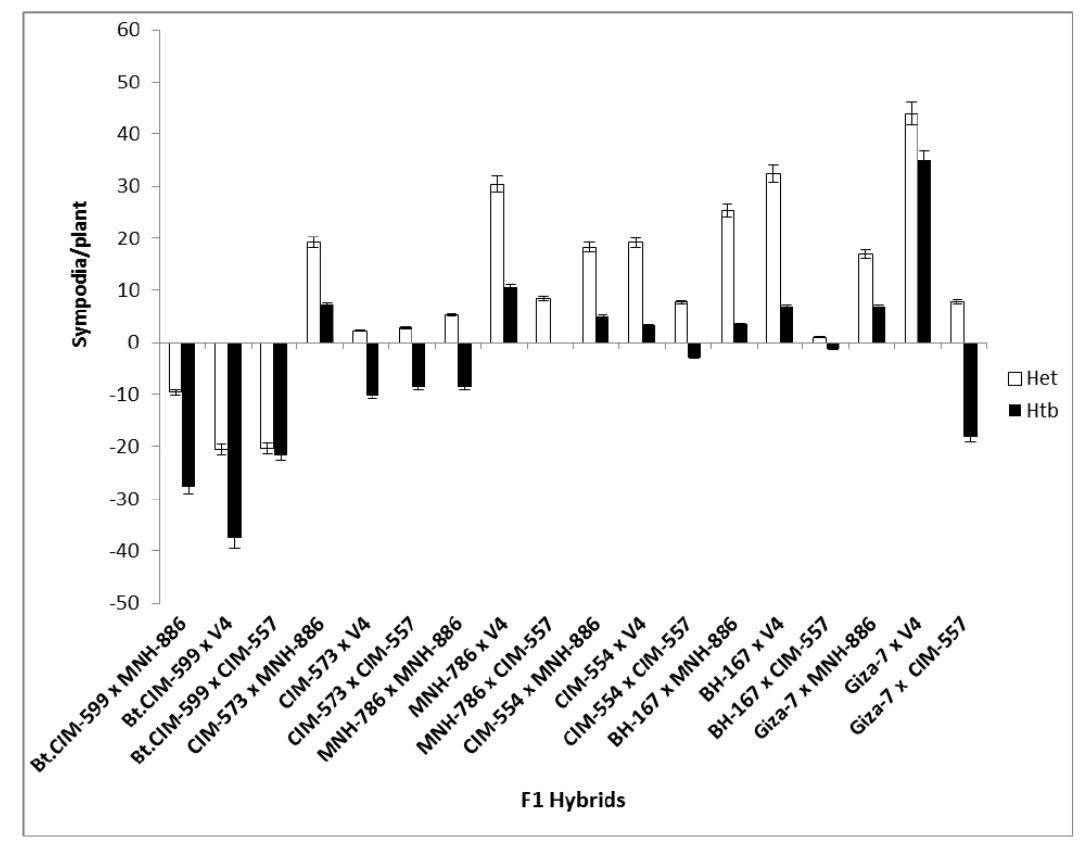

Figure 2. Results of heterosis and heterobeltosis for sympodia/plant in intraspecific and interspecific hybrids.

For seed index, 13 of 15 intraspecific hybrids exhibited negative heterosis. The maximum negative value was given by BH-167 x MNH-886 for heterosis (-20.13) (2 Table) and the $\mathrm{BH}-167 \mathrm{x}$ MNH-886 hybrid gave the maximum negative value for heterobeltiosis (-28.06). Regarding lint index, among intraspecific hybrids, the highest heterosis value was 
observed in MNH-786 x CIM-55 (11.03). The MNH-786 x CIM-557 cross had the maximum value for heterobeltiosis (9.90). All interspecific hybrids exhibited positive heterosis. The Giza-7 x V4 hybrid showed positive values for both heterosis (7.18) and heterobeltiosis (2.44). Figure 4 shows the heterosis and heterobeltiosis effects for lint weight/boll. The highest heterosis value was observed in the BH-167 x V4 (50.72) hybrid while the CIM-554 x CIM557 hybrid gave the highest heterobeltiosis value (41.75) for lint weight/boll. All intraspecific hybrids showed positive heterosis for GOT. Maximum heterosis was exhibited by the hybrid BH-167 x V4 (27.29). The highest positive value of heterobeltiosis was exhibited by BH-167 x V4 (19.16). Only one interspecific hybrid, Giza-7 x V4, exhibited positive heterosis and heterobeltiosis, which were11.14and 3.96, respectively (Figure 5).

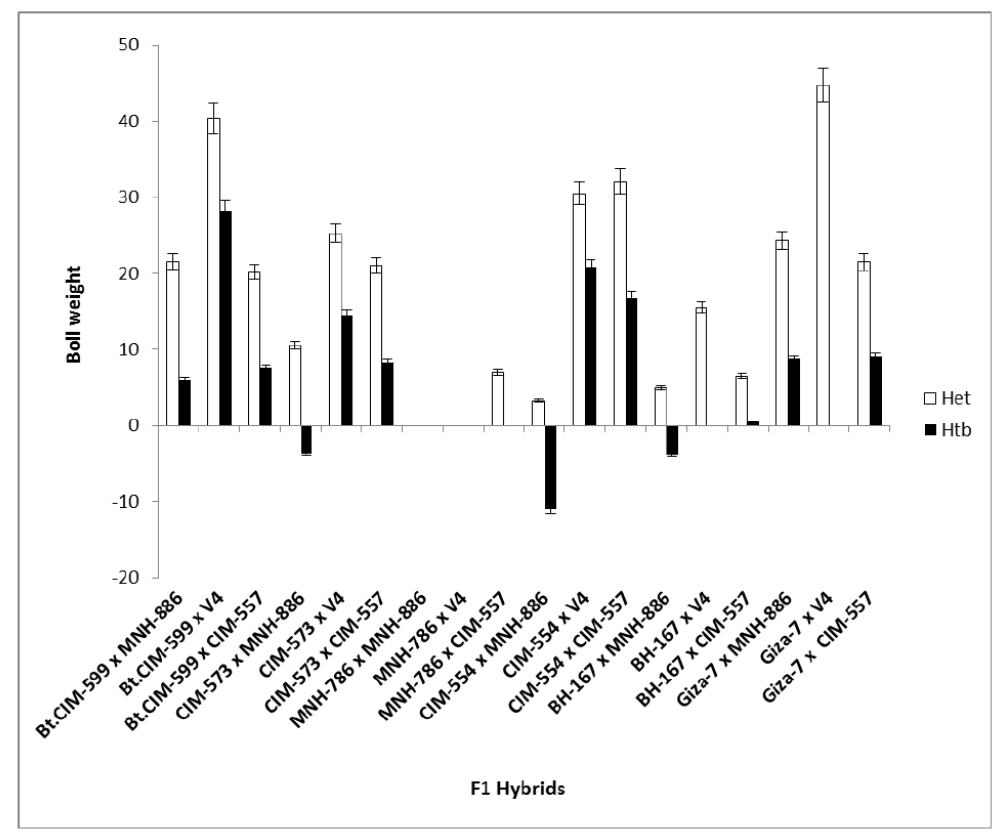

Figure 3. Results of heterosis and heterobeltosis for boll weight in intraspecific and interspecific hybrid.

Regarding seed cotton yield, the CIM-554 x CIM-557 cross exhibited the highest

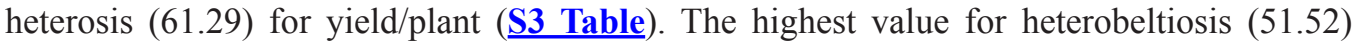
was given by the BH-167 x MNH-886 hybrid. The Giza-7 x MNH-886 hybrid showed the highest heterosis (114.77) and heterobeltiosis (109.00) values for yield/plant (Figure 6). All intraspecific and interspecific hybrids showed positive heterosis. The greater the micronaire value, the lower the fineness; therefore, a negative heterosis value is required for this trait. Giza-7 x MNH-886 was found to have negative a micronaire value, with heterosis and heterobeltiosis values of 10.29 and-19.16, respectively. Regarding staple length, CIM-554 x CIM-557 gave the highest values for heterosis (3.84) and heterobeltiosis (3.70) among all intraspecific hybrids; however, all interspecific hybrids gave positive heterobeltiosis and heterosis values. The Giza-7 x CIM-557 hybrid exhibited the highest values for heterosis (26.13) and heterobeltiosis (21.46). All interspecific hybrids showed positive heterobeltiosis 
and heterosis values for staple strength (S3 Table). Interspecific hybrids showed higher heterosis and heterobeltiosis values as compared with intraspecific hybrids for staple strength. The Giza-7 x V4 hybrid showed the highest values of heterosis (17.64) and heterobeltiosis (14.01) for staple strength.

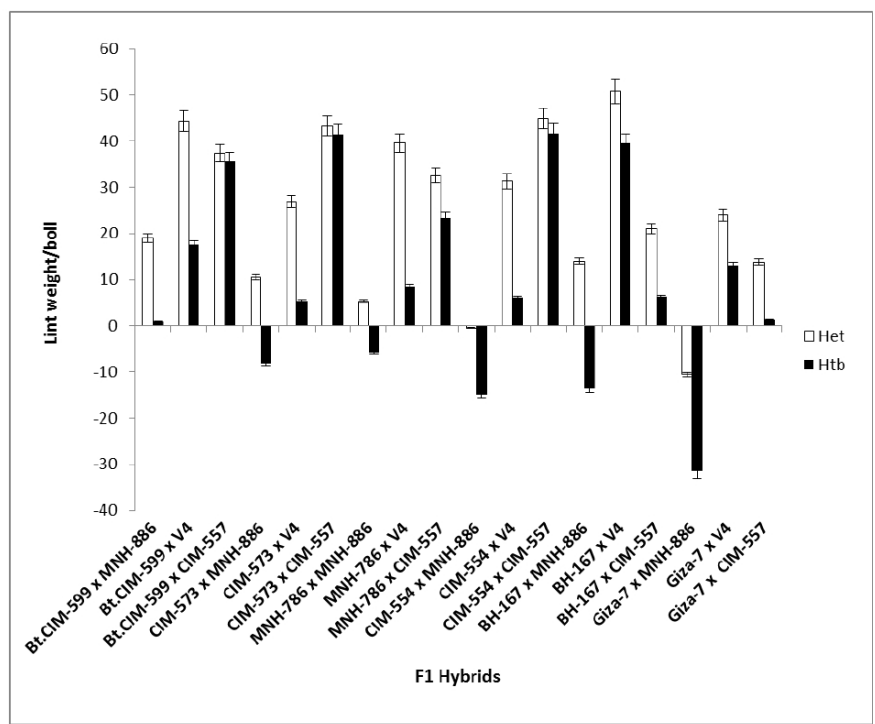

Figure 4. Results of heterosis and heterobeltosis for lint weight/boll in intraspecific and interspecific hybrids.

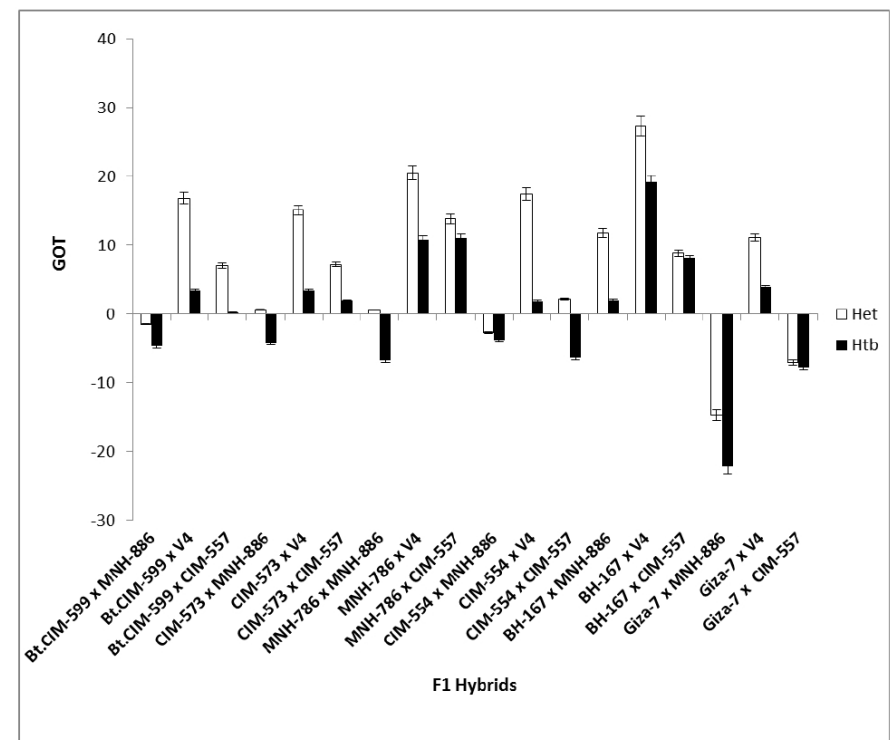

Figure 5. Results of heterosis and heterobeltosis for GOT in instraspecific and interspecific hybrids. 


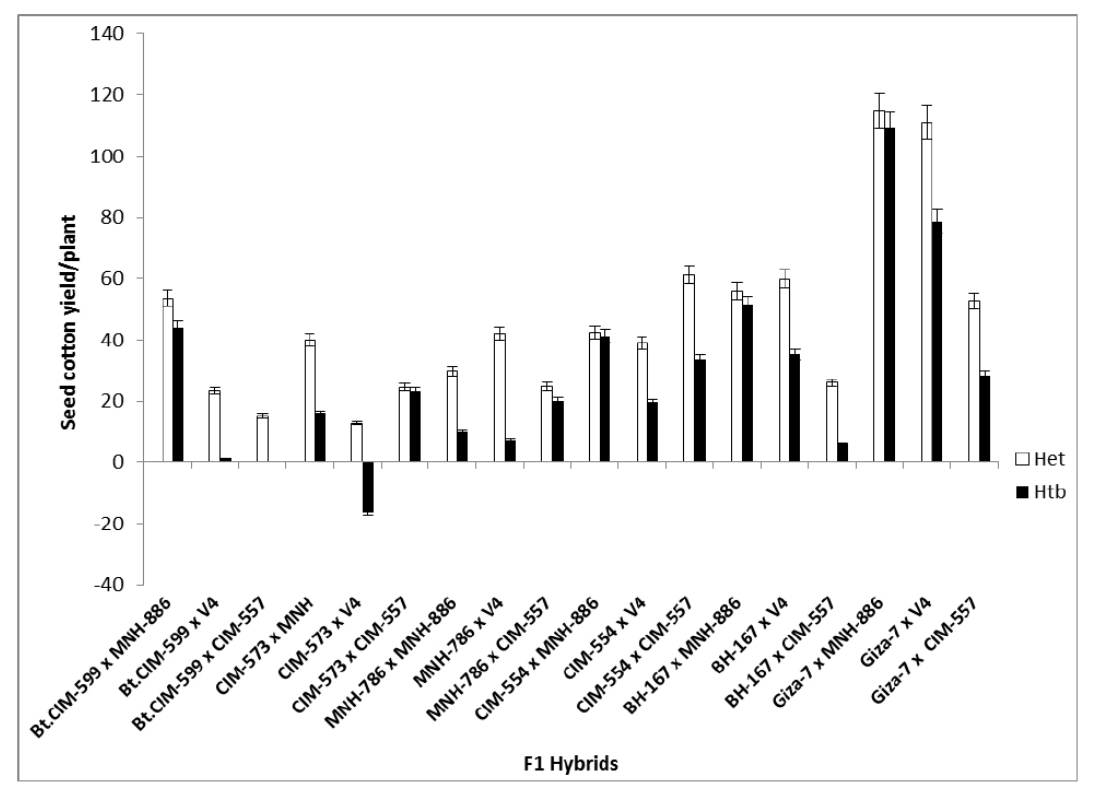

Figure 6. Results of heterosis and heterobeltosis for seed cotton yield/plant in intraspecific and interspecific hybrids.

\section{Correlation analysis}

Correlation coefficients were analyzed to investigate the association between traits and to distinguish the desirable traits that are useful in breeding from those that are undesirable (Falconer, 1981). Table 1 represents the correlation matrix for yield, yield components, and fiber traits.

Table 1. Correlation matrix between yield, yield-contributing traits, and fiber traits.

\begin{tabular}{|c|c|c|c|c|c|c|c|c|c|c|c|c|c|c|c|c|c|c|c|}
\hline Variables & TBP & Mono & Sym & NFB & TN & $\mathrm{FN}$ & BW & SB & SI & LW & LI & GOT & SCS & LS & MIC & SL & SS & SWS & $\mathrm{Y} / \mathrm{P}$ \\
\hline TBP & 1 & 0.32 & 0.48 & 0.32 & 0.64 & 0.28 & 0.05 & 0.01 & 0.18 & -0.09 & -0.06 & -0.18 & 0.10 & -0.07 & -0.25 & 0.53 & 0.26 & 0.21 & 0.74 \\
\hline Mono & 0.32 & 1 & -0.38 & 0.31 & -0.16 & 0.38 & -0.31 & -0.49 & 0.35 & -0.41 & -0.14 & -0.36 & 0.19 & -0.05 & -0.48 & 0.04 & -0.29 & 0.35 & 0.04 \\
\hline Sym & 0.48 & -0.38 & 1 & -0.19 & 0.85 & -0.08 & 0.08 & 0.34 & -0.31 & 0.14 & 0.03 & 0.24 & -0.26 & -0.17 & 0.11 & 0.24 & 0.29 & -0.27 & 0.29 \\
\hline NFB & 0.32 & 31 & -0.19 & 1 & -0.10 & 0.37 & 0.02 & -0.23 & 0.52 & -0.08 & 0.09 & -0.12 & 0.33 & 0.25 & -0.15 & 0.23 & -0.08 & 0.52 & 0.28 \\
\hline $\mathrm{TN}$ & 0.64 & 0.16 & 0.85 & $\frac{1}{-0.10}$ & 1 & 0.13 & 0.02 & 0.30 & $\frac{0.02}{-0.17}$ & 0.17 & 0.02 & 0.13 & $\begin{array}{l}-0.03 \\
\end{array}$ & -0.01 & 0.06 & 0.39 & 0.33 & $\begin{array}{c}0.0 .13 \\
\end{array}$ & 0.46 \\
\hline $\mathrm{FN}$ & 0.28 & 38 & -0.08 & 0.37 & 0.13 & 1 & 0.13 & 0.10 & 0.17 & 0.05 & -0.09 & -0.01 & 0.06 & 0.0 & -0.38 & 0.20 & -0.07 & 0.18 & 0.36 \\
\hline BW & .05 & 31 & 0.08 & 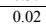 & 0.22 & 0.13 & 1 & 0.60 & 0.28 & 0.89 & 0.72 & 0.27 & 0.42 & 0.74 & 0.39 & 0.15 & 0.48 & 0.32 & 0.62 \\
\hline SB & 0.01 & & 0.3 & -0.2 & & 0.10 & 0.60 & 1 & -0.46 & 0.82 & 0.15 & 0.75 & -0.46 & 0.0 & 0.3 & -0.33 & 0.16 & -0.45 & 0.27 \\
\hline SI & 0.18 & .35 & -0.31 & 0.52 & -0.17 & 0.17 & 0.28 & -0.46 & 1 & -0.01 & 0.59 & -0.51 & 0.81 & 0.6 & -0.16 & 0.43 & 0.28 & 0.99 & 0.43 \\
\hline $\mathrm{LW}$ & $\begin{array}{l}-0.09 \\
-10\end{array}$ & & 0.14 & & 0.17 & 0.05 & 0.89 & 0.82 & -0.01 & 1 & 0.61 & 0.66 & 0.0 & 0.5 & 0. & $\begin{array}{l}-0.16 \\
-16\end{array}$ & 0.35 & 0.01 & 0.41 \\
\hline LI & -0.06 & -0.14 & 0.03 & 0.09 & 0.02 & -0.09 & 0.72 & 0.15 & 0.59 & 0.61 & 1 & 0.08 & 0.55 & 0.79 & 0.26 & 0.21 & 0.52 & 0.62 & 0.43 \\
\hline GOT & -0.18 & -0.36 & 0.24 & -0.12 & 0.13 & -0.01 & 0.27 & 0.75 & -0.51 & 0.66 & 0.08 & 1 & -0.56 & 0.08 & 0.47 & -0.44 & 0.02 & -0.51 & -0.08 \\
\hline SCS & 0 & 0.19 & -0.26 & 0.3 & -0.0 & 0.06 & 0.42 & -0.46 & 0.81 & 0.02 & 0.55 & -0.56 & 1 & 0.7 & -0.06 & 0.60 & 0.36 & 0.85 & 0.41 \\
\hline LS & -0.07 & -0.05 & -0.17 & 0.25 & -0.01 & 0.09 & 0.74 & 0.05 & 0.60 & 0.57 & 0.7 & 0.08 & 0.76 & 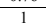 & 0.30 & 0.37 & 0.45 & 0.65 & 0.43 \\
\hline MIC & -0.25 & -0.48 & 0.11 & $\begin{array}{l}-0.15 \\
\end{array}$ & 0.06 & -0.38 & 0.39 & 0.39 & $\begin{array}{l}-0.16 \\
-0.16\end{array}$ & 0.51 & 0.26 & 0.47 & $\begin{array}{l}-0.06 \\
\end{array}$ & 0.30 & 1 & $\frac{0.19}{-0.19}$ & 0.25 & $\begin{array}{l}-0.20 \\
\end{array}$ & -0.02 \\
\hline $\mathrm{SL}$ & 0.53 & 0.04 & 0.24 & 0.23 & 0.39 & 0.20 & 0.15 & -0.33 & 0.43 & -0.16 & 0.21 & -0.44 & 0.60 & 0.3 & -0.19 & 1 & 0.55 & 0.47 & 0.59 \\
\hline SS & 0.26 & -0. & 0.2 & -0.08 & 0. & -0.07 & 0.48 & 0.16 & 0.28 & 0.35 & 0 & 0.02 & 0.36 & 0.45 & 0.25 & 0.55 & 1 & 0.28 & 0.54 \\
\hline SWS & 0.21 & 0.35 & -0.27 & 0.52 & -0.1 & 0.18 & 0.32 & -0.45 & 0.99 & 0.01 & 0.62 & -0.51 & 0.8 & 0.6 & -0.20 & 0.47 & 0.28 & 1 & 0.46 \\
\hline $\mathrm{Y} / \mathrm{P}$ & 0.74 & 0.04 & 0.29 & 0.28 & 0.46 & 0.36 & 0.62 & 0.27 & 0.43 & 0.41 & 0.43 & -0.08 & 0.41 & 0.43 & $\begin{array}{l}-0.02 \\
\end{array}$ & 0.59 & 0.54 & 0.46 & 1 \\
\hline
\end{tabular}

Values in bold are significant at $\alpha=0.05, \mathrm{TBP}=$ Bolls/plant, Sym $=$ Sympods $/$ plant, NFB $=$ Nodes of first fruiting branch, $\mathrm{TN}=$ Total nodes, $\mathrm{FN}=$ fruiting nodes, $\mathrm{BW}=$ Boll weight, $\mathrm{SB}=$ Seeds/boll, $\mathrm{SI}=\mathrm{Seed}$ index, $\mathrm{LI}=\mathrm{Lint}$ index, LW $=$ Lint weight/boll, GOT $=$ Ginning out turn, $\mathrm{SCS}=$ Seed cotton $/$ seed, LS $=$ Lint $/$ seed, SWS $=$ Seed weight/seed, YP = Yield/plant, SL = Staple length, SS = Staple strength, MIC = Micronaire value. 
The trait bolls/plant was positively correlated with the number of monopodia, sympodia, total nodes, NFB, boll weight, fruiting nodes, seeds/boll, seed cotton/seed, staple length, staple strength, seed weight/seed, and seed cotton yield/plant. Negative correlations were observed between bolls/plant with lint weight, lint index, ginning out turn, lint/seed, and micronaire value. A positive correlation was found between bolls/plant and seed cotton yield/plant (0.74), followed by staple length (0.53), and sympodia (0.48). A positive but nonsignificant correlation was observed between monopodia/plant and seed cotton yield/plant. The association between monopodia/plant and yield was not strong. A positive and significant correlation was found between sympodia and bolls/plant (0.48). A positive correlation was also found between fruiting nodes and bolls/plant (0.28), and a negative and non-significant association was observed for fruiting nodes with lint index (-0.09) and GOT (-0.01). A positive and significant correlation was found between boll weight and seeds/boll, lint index, lint weight, and lint/seed, respectively (Table 1). Furthermore, a positive but non-significant association was observed between boll weight and GOT. Boll weight was strongly associated with yield (0.62). A positive and significant correlation was found between boll weight and seeds/boll (0.60), while a positive but non-significant correlation was found between seeds/ boll and lint index (0.15). The trait seeds/boll was significantly and positively correlated with GOT (0.75) but negatively correlated with seed index (-0.46). Seed cotton/seed $(0.41)$, seed weight/seed (0.46), and lint/seed (0.43) were positively associated with seed cotton yield/ plant. Seed weight/seed exhibited a strong positive association with seed index, which was significantly and positively correlated with lint index (0.59) and seed cotton yield (0.43). GOT was negatively correlated (-0.08) with seed cotton yield/plant.

Staple strength and length were positively correlated with seed cotton yield/plant. Staple length and staple strength were positively correlated (0.55). A positive association was found among different fiber traits. The micronaire value was negatively but non-significantly associated with seed cotton yield.

\section{DISCUSSION}

In this study, heterosis and heterobeltiosis were measured using Fonseca and Patterson's

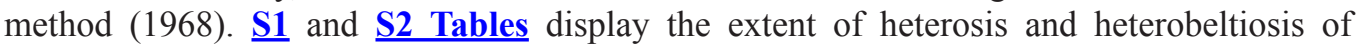
intraspecific and interspecific hybrids for traits contributing to yield. Significant heterosis was observed for all traits under investigation. All hybrids, whether interspecific or intraspecific, exhibited a range of heterosis and heterobeltiosis values for different traits. Positive heterosis and heterobeltiosis values were found for the traits bolls/plant, monopodia/plant, sympodia/ plant, and fruiting nodes ( $\underline{\mathbf{S 1} \text { Table }})$. Significant heterosis and heterobeltiosis values have previously been reported for bolls/plant (Rauf et al., 2005), monopodia/plant (Katageri and Kadapa, 1989; Hussain et al., 1990), and sympodia/plant (Keerio et al., 1996). Interspecific hybrids showed high heterosis and heterobeltiosis values for fruiting nodes. Marani (1968) reported that boll number heterosis resulted from of a higher number of fruiting nodes in $G$. barbadense; therefore, heterosis for boll number and for fruiting nodes is important for higher seed cotton yield.

Heterosis was found for boll weight, seeds/boll, seed index, lint index, and GOT (S2 Table). Dong et al. (2007) used a 4 x 5 (line x tester) experimental design and observed heterosis for boll weight and GOT. However, higher levels of heterosis for bolls/plant and 
boll weight than for GOT have been previously reported (Wu et al., 2004). In the present study, the interspecific hybrids Giza-7 x MNH-886 (52.77) and Giza-7 x V4 (44.73) showed the highest degree of heterosis for bolls/plant and boll weight, while for GOT, the highest magnitude was found for the intraspecific hybrids BH-167 x V4 (27.29). Interspecific hybrids usually provide lower values of heterosis for GOT because of positive heterosis in the seed index (Marani, 1967).

Several researchers have reported a range of heterobeltiosis and heterosis values for boll weight (Hussain et al., 1990; Rauf et al., 2005), seeds/boll (Hussain et al., 1990), seed index (Karande et al., 2004), lint index (Geddam et al., 2011), and GOT (Meredith and Brown, 1998; Soomro, 2000; Rauf et al., 2005). However, negative heterosis is desirable for seed index since the hybrids produce more lint (Geddam et al., 2011). S2 Table shows that 13 intraspecific hybrids exhibited heterosis in a desirable direction for seed index.

Heterosis for seed cotton yield is a main objective for cotton breeding. Interspecific hybrids generated a higher range of heterosis than did intraspecific hybrids. The interspecific hybrid Giza-7 x MNH-886 showed heterosis of up to $114.77 \%$, while the intraspecific hybrids, CIM-554 x CIM-557, showed heterosis of up to $61.29 \%$ and was consistent with that reported by Soomro et al. (1996), who noted $157.2 \%$ heterosis in interspecific hybrids and $33.7 \%$ in intraspecific hybrids. Rauf et al. (2005) reported that most hybrids resulting from 20 crosses showed positive heterosis and heterobeltiosis for seed cotton yield, and gave a wide range of heterosis and heterobeltiosis, i.e., -8.53 to $111.7 \%$ and -18.8 to $89.94 \%$, respectively.

Positive and negative heterosis were found for fiber traits as well as for heterobeltiosis. The greater the micronaire value, the lower the fineness; therefore, negative heterosis is required for fineness. Positive and negative values for heterosis and heterobeltiosis have been reported for micronaire value, staple length (Soomro, 2000; Rauf et al., 2005), and staple strength (Rauf et al., 2005). Interspecific hybrids showed higher heterosis and heterobeltiosis values than were observed for intraspecific hybrids for staple strength and length.

The results showed that there was a wide range of heterosis and heterobeltiosis for bolls/plant, boll weight, and seed cotton yield/plant. Heterosis was observed for all the attributes studied; however, interspecific hybrids showed more heterosis for seed cotton yield/ plant, staple length, staple strength, and bolls/plant, while intraspecific hybrids showed more heterosis for GOT. Interspecific hybrids have lower fiber fineness than do intraspecific hybrids, and due to increased hybrid vigor in the trait monopodia/plant, the rate of insect infestation also increases. Therefore, both hybrids can be used in future toobta in genotypes with high yield, early maturation, and increased resistance to biotic and abiotic stresses.

The correlation coefficient describes the association between several traits (Rasheed et al., 2009), and there for eaids selection. A positive and significant correlation was found between bolls/plant and seed cotton yield/plant followed by staple length and sympodial branches. This shows that an increase in one trait results in an increase in the value of another trait (Do-Thi-Haan et al., 2008). The correlation matrix (Table 1) revealed that the association between monopodia/plant and yield was not strong, and would not be a good selection criterion for yield. Apart from bolls/plant, boll weight is a very important trait that contributes to yield. Boll weight is strongly associated with seed cotton yield and could be used as a selection criterion in breeding programs. Boll weight showed a positive but non-significant association with GOT (Tyagi et al. 2014). A positive association was observed for boll weight with bolls/ plant, and for bolls/plant with seed cotton yield (Thiyagu et al., 2010). A similar association 
was observed in the present study and the results are presented in Table 1. This shows that an increase in one trait enhances the effect of other traits. A significant and positive correlation was found between boll weight and seeds/boll, while a positive but non-significant correlation was found between seeds/boll and lint index. Seeds/boll was significantly and positively correlated with GOT, but was negatively correlated with seed index (Desalegn et al., 2009). Staple strength and staple length were positively correlated with seed cotton yield/plant. A positive correlation between staple length and strength was reported by Basbag and Gencer (2007). Zhan et al. (2013) reported a non-significant negative association between micronaire value and seed cotton yield. Similarly, a negative but non-significant association was found between micronaire value and seed cotton yield/plant (-0.02) in the present study (Table 1). Positive associations between different traits suggest that future selection based on these traits will help in the development of high yielding varieties.

In conclusion, these results indicate that interspecific hybrids show more heterosis than do intraspecific hybrids. Higher levels of heterosis indicate the existence of a broad genetic base among parents, since distant hybridizations have more potential to transfer genes for better fiber quality, yield contributing traits and seed cotton yield. As such, a higher level of heterosis was observed for yield, most of the yield contributing traits, and for fiber traits in interspecific hybrids. Higher heterotic effects for GOT were exhibited in intraspecific hybrids as compared with interspecific hybrids, in which GOT heterotic effects were lower due to a higher level of heterosis in the seed index. Correlation analysis also revealed that bolls/ plant, sympodia/plant, fruiting nodes, seed index, boll weight, lint weight/boll, lint index, lint/seed, staple length, and staple strength were positively correlated with seed cotton yield. However, interspecific hybrids gave high heterosis for bolls/plant, sympodia/plant, fruiting nodes, boll weight, but low heterosis for fiber fineness. Despite interspecific hybrids exhibiting high heterosis for seed cotton yield, they are currently not used commercially due to insect infestation. Introducing insect pest and disease resistance to such hybrids may generate better genotypes for their subsequent cultivation. For intraspecific hybrids, the main contribution to seed cotton yield was from boll number and boll weight. Higher heterosis for seed cotton yield, moderate heterosis for boll weight, and low heterosis for GOT were observed in intraspecific hybrids. Heterosis for fiber characters is lower than heterosis for morphological traits in intra-hirsutum hybrids, although these exhibit better fiber fineness as compared with interspecific hybrids. Interspecific hybrids have poor fiber fineness because of a higher mote content. However, interspecific hybrids have high heterosis potential for seed cotton yield and a low heterosis potential for GOT because of their higher seed index. Higher heterosis in interspecific hybrids may result from higher vegetative growth, and may lead to more fruiting nodes throughout the season. Therefore, both interspecific and intraspecific hybrids have their own importance as well as positive and negative aspects.

\section{Conflicts of interest}

The authors declare no conflict of interest.

\section{ACKNOWLEDGMENTS}

The authors would like to thank the Department of Plant Breeding and Genetics for providing assistance and experimental farms for this experiment. 


\section{REFERENCES}

Anonymous (2014). Pakistan Economic Survey. Ministry of Food and Agriculture, Division (Economic Wing) Government of Pakistan, Islamabad.

Azhar FM, Abid AR and Khan MA (1984). Association of yield with various economic characters in Gossypium hirsutum L. The Pak. Cotton 28: 127-134.

Basbag S and Gencer O (2007). Investigation of some yield and fibre quality characteristics of interspecific hybrid (Gossypium hirsutum L. x G. barbadense L.) cotton varieties. Hereditas 144: 33-42. http://dx.doi.org/10.1111/ j.2007.0018-0661.01962.x

Chen ZH, Wu FB, Wang XD and Zhang GP (2005). Heterosis in CMS hybrids of cotton for photosynthetic and chlorophyll fluorescence parameters. Euphytica 144: 353-361. http://dx.doi.org/10.1007/s10681-005-8188-y

Cole CB, Bowman DT, Bourland FM, Caldwell WD, et al. (2009). Impact of heterozygosity and heterogeneity on cotton lint yield stability. Crop Sci. 49: 1577-1585. http://dx.doi.org/10.2135/cropsci2008.08.0450

Coyle GG and Smith CW (1997). Combining ability for within boll yield components in cotton, Gossypium hirsutum L. Crop Sci. 37: 1118-1122. http://dx.doi.org/10.2135/cropsci1997.0011183X003700040014x

Desalegn Z, Ratanadilok N and Kaveeta R (2009). Correlation and heritability for yield and fiber quality parameters of Ethiopian cotton (Gossypium hirsutum L.) estimated from 15 (diallel) crosses. Kasetsart J. (Nat. Sci.) 43: 1-11.

Dong HZ, Li WJ, Tang W, Li ZH, et al. (2007). Heterosis in yield, endotoxin expression and some physiological parameters in Bt transgenic cotton. Plant Breed. 126: 169-175. http://dx.doi.org/10.1111/j.1439-0523.2007.01321.x

Dong J, Wu F, Jin Z and Huang Y (2006). Heterosis for yield and some physiological traits in hybrid cotton. Euphytica 151: 71-77. http://dx.doi.org/10.1007/s10681-006-9129-0

Do-Thi-Haan, Ravikesavan R and Iyanar K (2008). Genetic advance and heritability as a selection index for improvement of yield and quality in cotton. J. Cotton Res. Dev. 22: 14-18.

Falconer DS (1981). Introduction to quantitative genetics. 2nd edition. Longman, New York.

Fonseca S and Patterson FL (1968). Yield components, heritabilities and interrelationships in winter wheat (Triticum aestivum L.). Crop Sci. 8: 614-617. http://dx.doi.org/10.2135/cropsci1968.0011183X000800050032x

Galal HES, Miller PA and Lee JA (1966). Heterosis in relation to development in upland cotton Gossypium hirsutum L. Crop Sci. 6: 555-559. http://dx.doi.org/10.2135/cropsci1966.0011183X000600060016x

Geddam SB, Khadi BM, Mogali S, Patil RS, et al. (2011). Study of heterosis in genetic male sterility based diploid cotton hybrids for yield, yield component and fibre quality characters. Karnataka J. Agric. Sci. 24: 118-124.

Green CC and Culp TW (1990). Simultaneous improvement of yield, fiber quality and yarn strength in upland cotton. Crop Sci. 30: 66-69. http://dx.doi.org/10.2135/cropsci1990.0011183X003000010015x

Gupta SP and Singh TH (1987). Heterosis and inbreeding depression for seed cotton yield and some fiber attributes in upland cotton. J. Crop Improv. 14: 14-17.

Hussain A, Rafique M, Mahmood T, Khan MA, et al. (1990). Hybrids vigour in relation to development in cotton ( $G$. hirsutum L.). J. Agric. Res. 28: 205-217.

Iqbal M, Chang MA, Iqbal MZ, Hassan M, et al. (2003). Correlation and path co-efficient analysis of earliness and agronomic characters of upland cotton in Multan. Pak. J.Agron. 2: 160-168. http://dx.doi.org/10.3923/ja.2003.160.168

Jenkins JN, Gutierrez OA, McCarty JC and Wu J (2009). Genetic variance components and genetic effects among eleven diverse upland cotton lines and their $\mathrm{F}_{2}$ hybrids. Euphytica 167: 397-408. http://dx.doi.org/10.1007/s10681-009-9902-y

Karande SS, Wandhare MR, Ladole MY, Waode MM, et al. (2004). Heterosis and combining ability studies in interspecific diploid cotton hybrids for fibre quality parameters. International Symposium on strategies for sustainable cotton production, A Global Vision. University of Agriculture Sciences, Dharwad, Karnataka, India, 23-25.

Katageri IS and Kadapa SN (1989). Heterosis for yield components characters in boll worm tolerant Gossypium hirsutumxG. barbadense L. cotton hybrid. Indian J. Genet. 49: 107-112.

Katageri IS, Kapada SN, Khadi BM, Eshanna MR, et al. (1991). Hybrid vigor and combining ability in intrabarbadense hybrid cotton. Karnataka J. Agric. Sci. 4: 121-125.

Keerio MD, Kalwar MS, Memon MI and Baloch MJ (1996). Estimates of economic heterosis for some metrical traits of Gossypium hirsutum L. The Pak. Cotton 40: 42-46.

Marani A (1967). Heterosis and combining ability in intraspecific and interspecific crosses of cotton. Crop Sci. 7: 519-522. http://dx.doi.org/10.2135/cropsci1967.0011183X000700050033x

Marani A (1968). Heterosis and inheritance of quantitative characters in interspecific crosses of cotton. Crop Sci. 8: 299303. http://dx.doi.org/10.2135/cropsci1968.0011183X000800030012x

Meredith RW and Brown SJ (1998). Heterosis and combining ability of cottons originating from different regions of the United States. J. Cotton Sci. 2: 77-84. 
Rasheed A, Malik W, Khan AA, Murtaza N, et al. (2009). Genetic evaluation of fibre yield and yield components in fifteen cotton (Gossypium hirsutum) genotypes. Int. J. Agric. Biol. 11: 581-585.

Rauf S, Khan TM and Nazir S (2005). Combining ability and heterosis in Gossypium hirsutum L. Int. J. Agric. Biol. 7: 109-113.

Soomro AR, Nachnani GR, Soomro AW and Kalhoro AD (1996). Heterosis for yield in tetraploid cotton hybrids and their reciprocals. The Pak. Cotton 40: 18-23.

Soomro ZA (2000). Genetic architecture of quantitative and qualitative traits in Gossypium hirsutum L. M.Phil. Thesis, Department of Plant Breeding and Genetics, Sindh Agriculture University,Tandojam, Sindh, Pakistan.

Tang B, Jenkins JN, McCarty JC and Watson CE (1993). F hybrids of host plant germplasm and cotton cultivars: Heterosis and combining ability for lint yield and yield components. Crop Sci. 33: 700-705. http://dx.doi.org/10.2135/cropsci 1993.0011183X003300040012x

Thiyagu K, Nadarajan N, Rajarathinam S, Sudhakar D, et al. (2010). Association and path analysis for seed cotton yield improvement in interspecific crosses of cotton (Gossypium spp). Electr. J. Plant Breed. 1: 1001-1005.

Tyagi P, Bowman DT, Bourland FM, Edmisten K, et al. (2014). Components of hybrid vigor in upland cotton (Gossypium hirsutum L.) and their relationship with environment. Euphytica 195: 117-127. http://dx.doi.org/10.1007/s10681013-0987-y

Worley S, Culp TW and Harrel DC (1974). The relative contribution of yield components to yield in upland cotton Gossypium hirsutum. Euphytica 23: 399-403. http://dx.doi.org/10.1007/BF00035885

$\mathrm{Wu}$ YT, Yin JM, Guo WZ, Zhu XF, et al. (2004). Heterosis performance of yield and fibre quality in $\mathrm{F}_{1}$ and $\mathrm{F}_{2}$ hybrids in upland cotton. Plant Breed. 123: 285-289. http://dx.doi.org/10.1111/j.1439-0523.2004.00990.x

Zeng L and Wu J (2012). Germplasm for genetic improvement of lint yield in Upland cotton: Genetic analysis of lint yield with yield components. Euphytica 187: 247-261. http://dx.doi.org/10.1007/s10681-012-0708-y

Zhan YJ, Yang T, Sun JC, Zhuang SR, et al. (2013). Genetic correlation analysis of early maturity yield and quality in special-early mature Gossypium hirsutum L. Res. Agri. Modern. 2013-01.

Zhou YY (1986). Yield components in upland cotton. Acta Agric. Univ. Pekinensis 12: 269-274.

\section{Supplementary material}

S1 Table. Estimates of heterosis and heterobeltiosis for morphological traits among intraspecific and interspecific hybrids.

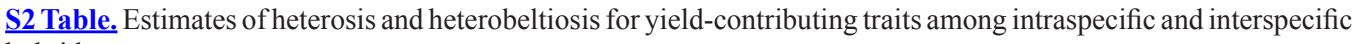
hybrids.

S3 Table. Estimates of heterosis and heterobeltiosis for seed cotton yield and fiber traits among intraspecific and interspecific hybrids. 